\title{
PENGEMBANGAN PERANGKAT PEMBELAJARAN MIKROBIOLOGI BERBASIS E-LEARNING UNTUK MEMBANGUN KETERAMPILAN ARGUMENTASI CALON GURU IPA
}

\author{
Liska Berlian*1, Annisa Novianti Taufik ${ }^{2}$, Atep Iman $^{3}$ \\ 1,2Program Studi Pendidikan IPA, FKIP, Universitas Sultan Ageng Tirtayasa, Serang \\ ${ }^{3}$ Program Studi Pendidikan Teknik Mesin, FKIP, Universitas Sultan Ageng Tirtayasa, Serang \\ e-mail: *1liska.berlian@untirta.ac.id, ${ }^{2}$ annisa@untirta.ac.id, ${ }^{3}$ atepiman@untirta.ac.id
}

\begin{abstract}
ABSTRAK
Tujuan penelitian ini untuk mengembangkan perangkat pembelajaran mata kuliah Mikrobiologi yang layak digunakan, dimana perangkat pembelajaran yang dikembangkan berbasis e-learning untuk membangun keterampilan argumentasi mahasiswa calon guru IPA. Jenis penelitian yang digunakan dalam penelitian adalah penelitian dan pengembangan (Research and Development/R\&D). Kelayakan perangkat pembelajaran dilakukan dengan menguji kevalidan dan keefektifan produk tersebut. Penelitian dilakukan pada 22 mahasiswa semester V di jurusan Pendidikan IPA, Fakultas Keguruan dan Ilmu Pendidikan, Universitas Sultan Ageng Tirtayasa. Hasil analisis penelitian menyatakan bahwa perangkat pembelajaran yang dikembangkan berada pada kategori sangat valid setelah dilakukan uji kevalidan oleh Expert Judgement, serta sangat efektif setelah dilakukan analisis uji keefektifan dengan menggunakan instrumen penilaian keterampilan argumentasi. Maka disimpulkan bahwa perangkat pembelajaran mata kuliah Mikrobiologi yang dikembangkan layak untuk digunakan.
\end{abstract}

Kata kunci : Perangkat, Pembelajaran, E-Learning, Keterampilan, Argumentasi.

\begin{abstract}
This study aimed to develop learning tools that are proper to use, where the learning tools developed are based on e-learning in a Microbiology course to increase the argumentation skill of undergraduate students of the science teacher candidates. The type of research used in this study is Research and Development $(R \& D)$. The proper learning tools are conducted by testing the validity and effectiveness of the product. This research was conducted on 22 undergraduate students at the Department of Science Education, Faculty of Teacher Training and Education, Universitas Sultan Ageng Tirtayasa, Indonesia. The analysis results stated that e-learning-based learning tools which be developed were proper for using in Microbiology course because after going through the stages of validation, small groups trial, and product revision, the validity criteria of learning tools are in very valid criteria and based on the effectiveness test of learning tools are in very effective criteria. Then it is concluded that learning tools developed are proper to use.

Keywords : Learning, Tools, e-Learning, Skill, Argumentation
\end{abstract}




\section{PENDAHULUAN}

Perangkat pembelajaran adalah bagian dari serangkaian persiapan seorang pendidik sebelum melaksanakan proses pembelajaran. Prasetyo dkk (2011) mengemukakan bahwa seorang pendidik sebelum memulai atau mempersiapkan pembelajaran harus menyusun suatu perlengkapan atau alat yang memungkinkan peserta didik dan pendidik dapat melaksanakan proses kegiatan belajar mengajar yang disebut perangkat pembelajaran. Di dalam Peraturan Menteri Pendidikan dan Kebudayaan No. 65 Tahun 2013 tentang Standar Proses Pendidikan Dasar dan Menengah dijelaskan bahwa penyusunan perangkat pembelajaran merupakan bagian dari perencanaan pembelajaran. Perencanaan pembelajaran dirancang dalam bentuk silabus dan Rencana Pembelajaran Semester (RPS) yang mengacu pada standar isi. Setelah menyiapkan perencanaan pembelajaran, seorang pendidik juga harus menyiapkan seperangkat skenario pembelajaran, sumber belajar dan perangkat penilaian. Menurut Nazarudin (2007), perangkat pembelajaran adalah berbagai persiapan yang dirancang oleh pendidik secara individu atau pun berkelompok agar pelaksanaan pembelajaran dan evaluasi pembelajaran yang telah disiapkan dapat dilaksanakan secara sistematis dan mendapatkan hasil sesuai dengan yang diharapkan.

Pada penelitian ini dikembangkan perangkat pembelajaran berupa RPS dan bahan ajar yang berbasis e-learning pada mata kuliah Mikrobiologi. Salah satu bentuk upaya perbaikan kualitas pembelajaran adalah dengan adanya penggunaan internet untuk mendukung sistem pembelajaran konvensional yang terdapat keterbatasan dalam pelaksanaan pembelajarannya. Teknologi informasi pada saat ini terutama pada abad 21 berkembang sangat pesat sehingga mau tidak mau hal ini juga mengakibatkan perubahan pada dunia pendidikan. Untuk menghadapi perubahan tersebut, maka suka atau pun tidak suka peserta didik juga dituntut untuk mempunyai keterampilan berpikir kritis, keterampilan berpikir kreatif, pengetahuan dan kemampuan literasi digital, literasi informasi, literasi media, serta menguasai komunikasi dan teknologi informasi (Frydenberg \& Andone, 2011). Oleh karena itu, agar pembelajaran pada abad 21 dapat sukses, para pendidik harus merancang desain pembelajaran yang mampu memuat keterampilan abad 21.

Mata kuliah Mikrobiologi merupakan salah satu mata kuliah bidang keilmuan di jurusan Pendidikan IPA, Fakultas Keguruan dan Ilmu Pendidikan, Universitas Sultan Ageng Tirtayasa (Untirta). Mata kuliah Mikrobiologi membahas mengenai pemahaman mahasiswa dalam menjaga kebersihan sandang, pangan, dan papan serta memiliki banyak keterkaitan dengan makhluk hidup mikroskopis yang mempunyai dampak menguntungkan sekaligus merugikan bagi kehidupan manusia. Selama ini, pembelajaran pada mata kuliah Mikrobiologi lebih banyak menggunakan metode ceramah, hal ini dirasa belum terlalu efektif dalam membangun pemahaman mahasiswa serta belum mampu merangsang keterampilan komunikasi mahasiswa khususnya keterampilan argumentasi mahasiswa calon guru IPA. Oleh karena itu, diperlukan upaya perbaikan pembelajaran dengan menggunakan pembelajaran berbasis online atau e-learning, sehingga diharapkan mahasiswa dapat lebih berperan aktif dalam membangun pemahamannya serta dapat lebih memaksimalkan kemampuan komunikasinya khususnya keterampilan argumentasi. Argumentasi adalah proses pembelajaran yang sangat penting dalam pembelajaran sains sehingga sangat perlu dibelajarkan di kelas sains sebagai bagian dari penyelidikan ilmiah dan literasi (Erduran et al, 2015). Demircioglu dan Ucar (2012) juga menjelaskan bahwa keterampilan argumentasi sebagai bentuk komunikasi untuk mengeluarkan ide 
melalui wacana ilmiah merupakan proses yang sangat penting dalam pembelajaran biologi.

Koenenman et al (2013) menyatakan bahwa beberapa strategi pengajaran telah digunakan pada pendidikan menengah, tetapi tidak satu pun dari strategi ini berfokus secara khusus pada keterampilan argumentasi ilmiah. Macagno dan Konstantinidou (2012) menjelaskan bahwa hubungan antara pengajaran dan keterampilan argumentasi menjadi suatu masalah krusial di bidang pendidikan khususnya dalam pendidikan sains. Kulatunga et al (2013) menyatakan bahwa model pembelajaran argumentasi dapat digunakan untuk mengidentifikasi argumentasi peserta didik selama kerja kelompok dalam proses pembelajarannya. Selanjutnya dijelaskan oleh Gray dan Hwa (2014) yang menyatakan bahwa pengetahuan ilmiah dibangun dengan menggunakan metode inquiry seperti metode eksperimental sehingga keterampilan argumentasi yang dibangun selama pembelajaran sains dapat bervariasi tergantung pada topik atau konsep inquiry yang digunakan.

Harapannya, melalui pengembangan perangkat pembelajaran pada mata kuliah Mikrobiologi berbasis e-learning ini, mahasiswa tidak hanya memahami konsepkonsep Mikrobiologi saja, tetapi dapat mengaitkan secara ilmiah aplikasi dan peranan Mikrobiologi khususnya dalam bidang kesehatan terutama pada kondisi pandemi seperti ini. Melalui pengembangan perangkat pembelajaran ini juga diharapkan dapat meningkatkan keterampilan argumentasi mahasiswa calon guru IPA melalui kegiatan-kegiatan ilmiah selama proses pembelajaran. Sampson dan Blanchard (2012) menjelaskan bahwa keterlibatan peserta didik dalam argumentasi ilmiah dapat mendorong pemahaman yang lebih baik tentang konsep dan proses sains. Keterampilan argumentasi peserta didik sama pentingnya dengan sarana untuk meningkatkan pemahaman konseptual dan pemikiran kritis (Jin et al, 2015). Hasil penelitian
Ural dan Gençoğlan (2020) menunjukkan bahwa prestasi belajar peserta didik yang dibelajarkan dengan metode pembelajaran dengan pendekatan berbasis argumentasi lebih tinggi dari yang diajarkan dengan pendekatan pengajaran didaktik. Hal ini juga sejalan dengan apa yang diungkapkan oleh Bulgern et al (2014) menjelaskan bahwa peserta didik yang dibelajarkan dengan menggunakan metode argumentasi dan intervensi (AEI) lebih tinggi bila dibandingkan dengan metode pembelajaran konvensional.

Untuk menunjang hal tersebut, peneliti memandang bahwa dosen perlu menyusun perangkat pembelajaran berbasis $e$ learning yang akan dikaitkan dengan konsep-konsep pada mata kuliah Mikrobiologi. Perangkat pembelajaran mata kuliah Mikrobiologi berbasis $e$ learning ini diaplikasikan sejak awal perkuliahan dengan harapan dapat meningkatkan kompetensi dosen yang berdampak pada kualitas belajar mengajar serta dapat meningkatkan keterampilan argumentasi mahasiswa calon guru IPA. Keterampilan argumentasi dalam pembelajaran sangat diperlukan oleh mahasiswa karena dapat meningkatkan kemampuan komunikasinya sebagai seorang calon guru IPA dan dapat memotivasi kegiatan belajarnya. Dalam keterampilan argumentasi terdapat gambaran bagaimana mahasiswa seharusnya bersikap dalam belajar, menanggapi suatu permasalahan, menyampaikan dan mempertahankan argumentasi ilmiahnya dengan menyertakan bukti dan data serta melaksanakan suatu tugas, dan mengembangkan diri. Hal ini tentunya sangat mempengaruhi hasil dari kegiatan belajar mahasiswa ke arah yang positif. Melalui penanaman dan pengembangan keterampilan argumentasi dalam belajar, mahasiswa memiliki kemungkinan untuk lebih dapat belajar memahami dan menemukan.

Melaksanakan penelitian dan pengembangan Pendidikan IPA merupakan salah satu misi dari Jurusan Pendidikan 
IPA, Fakultas Keguruan dan Ilmu Pendidikan, Universitas Sultan Ageng Tirtayasa. Berdasarkan pada misi tersebut, penjabaran tujuan jurusan Pendidikan IPA, diantaranya adalah Menghasilkan calon Sarjana Pendidikan Ilmu Pengetahuan Alam (IPA) yang maju, bermutu, berkarakter dan berdaya saing serta Menghasilkan karya inovatif dalam bidang pendidikan IPA yang dapat diterapkan dalam pembelajaran IPA. Dari penjabaran tersebut, salah satu hal yang menunjang misi dan tujuan dari jurusan Pendidikan IPA di Fakultas Keguruan dan Ilmu Pendidikan, Universitas Sultan Ageng Tirtayasa dapat dilakukan salah satunya dengan melakukan penelitian dan pengembangan perangkat pembelajaran mata kuliah Mikrobiologi berbasis $e$ learning untuk meningkatkan keterampilan argumentasi mahasiswa calon guru IPA. Penelitian ini diarahkan untuk mengembangkan perangkat pembelajaran berbasis e-learning pada mata kuliah Mikrobiologi sehingga diharapkan dapat menumbuhkan dan meningkatkan keterampilan abad 21 khususnya keterampilan argumentasi mahasiswa calon guru IPA melalui pengembangan perangkat pembelajaran berbasis $e$ learning.

\section{METODE}

Jenis penelitian yang digunakan dalam penelitian adalah penelitian dan pengembangan (Research and Development $/ R \& D)$. Penelitian ini bertujuan untuk menghasilkan produk yang layak digunakan, dengan menguji kevalidan dan keefektifan produk tersebut. Dalam penelitian dan pengembangan, sebelum menghasilkan produk tertentu yang merupakan hasil penelitian, maka dilakukan tahapan analisis kebutuhan terlebih dahulu serta untuk menguji kevalidan dan keefektifan produk tersebut supaya dapat berfungsi di masyarakat luas maka diperlukan penelitian untuk menguji kevalidan dan keefektifan produk tersebut (Sugiyono, 2008). Pada penelitian ini produk yang dikembangkan berupa perangkat pembelajaran dalam bentuk RPS dan bahan ajar berbasis e-learning yang akan digunakan pada mata kuliah Mikrobiologi sehingga dapat menumbuhkan dan meningkatkan keterampilan argumentasi mahasiswa calon guru IPA. Penelitian bertempat di jurusan Pendidikan IPA, Fakultas Keguruan dan Ilmu Pendidikan, Universitas Sultan Ageng Tirtayasa.

Menurut Gall et al (2007) yang menggariskan langkah-langkah umum dalam penelitian dan pengembangan meliputi analisis kebutuhan, perencanaan, pengembangan format produk awal, validasi produk awal, revisi produk tahap awal, uji coba kelompok kecil, revisi produk, uji coba lapangan, revisi produk akhir serta desiminasi dan implementasi.

Pada penelitian ini, tahap pengembangan perangkat pembelajaran berbasis e-learning pada mata kuliah Mikrobiologi hanya pada ujicoba lapangan skala kecil. Pengumpulan data dan analisis data dalam penelitian ini yaitu berupa uji kevalidan dan keefektifan dari perangkat pembelajaran yang dikembangkan. Untuk memperoleh data kevalidan dari RPS dan bahan ajar yang dikembangkan, maka validator diberikan lembar penilaian beserta perangkat pembelajaran yang telah dikembangkan untuk menilai aspek format, aspek isi, dan aspek bahasa. Hasil penilaian kemudian dianalisis untuk mengetahui tingkat kevalidannya.

Tabel 1. Kriteria Tingkat Kevalidan

\begin{tabular}{cc}
\hline Nilai & Kriteria \\
\hline $3,5<$ Skor $\leq 4$ & Sangat Valid \\
\hline $2,5<$ Skor $\leq 3,5$ & Valid \\
\hline $1,5<$ Skor $\leq 2,5$ & Cukup Valid \\
\hline Skor $\leq 1,5$ & Tidak Valid \\
\hline
\end{tabular}


Pernyataan pada lembar angket respon mahasiswa mencakup kemenarikan, kemudahan, keterbantuan, dan pemecahan masalah. Adapun kriteria keefektifan pembelajaran menurut Rajabi dkk (2015), sebagai berikut :

Tabel 2. Kriteria Keefektifan Pembelajaran

\begin{tabular}{cc}
\hline Rentang & Kriteria \\
\hline $3,4-4$ & Sangat efektif \\
\hline $2,6-3,3$ & Efektif \\
\hline $1,7-2,5$ & Kurang efektif \\
\hline $1-1,6$ & Tidak efektif \\
\hline
\end{tabular}

Untuk menguji keefektifan dari perangkat pembelajaran mata kuliah Mikrobiologi dilakukan dengan menggunakan data keterampilan argumentasi mahasiswa calon guru IPA dianalisis dengan menggunakan pedoman penskoran berikut (Ridwan, 2013) :

Tabel 3. Pedoman Skor Keterampilan Argumentasi Mahasiswa

\begin{tabular}{cccc}
\hline $\begin{array}{c}\text { Pernyataan } \\
\text { Positif }\end{array}$ & Skor & $\begin{array}{c}\text { Pernyataan } \\
\text { Negatif }\end{array}$ & Skor \\
\hline $\begin{array}{c}\text { Sangat Setuju } \\
\text { (SS) }\end{array}$ & 4 & $\begin{array}{c}\text { Sangat Setuju } \\
(\text { SS) }\end{array}$ & 1 \\
$\begin{array}{c}\text { Setuju } \\
(\text { S) }\end{array}$ & 3 & $\begin{array}{c}\text { Setuju } \\
(\text { S) }\end{array}$ & 2 \\
$\begin{array}{c}\text { Tidak Setuju } \\
\text { (TS) }\end{array}$ & 2 & $\begin{array}{c}\text { Tidak Setuju } \\
(T S)\end{array}$ & 3 \\
Sangat & 1 & $\begin{array}{c}\text { Sangat } \\
\text { Tidak Setuju } \\
\text { (STS) }\end{array}$ & 4 \\
$\begin{array}{c}\text { Tidak Setuju } \\
\text { (STS) }\end{array}$ & & & \\
\hline
\end{tabular}

Untuk menghindari pernyataan dengan skor 0 , peneliti memastikan mahasiswa menjawab semua pernyataan kemampuan

argumentasi. Setelah dilakukan analisis data dengan menggunakan pedoman skor kemampuan argumentasi, selanjutnya skor dibuat dalam persentase dan dinyatakan dalam kriteria sebagai berikut (Arikunto : 2015)

Tabel 4. Kriteria Persentase Keterampilan Argumentasi Mahasiswa

\begin{tabular}{cc}
\hline Skor Penilaian & Kriteria \\
\hline $86 \%-100 \%$ & Sangat baik \\
\hline $71 \%-85 \%$ & Baik \\
\hline $56 \%-70 \%$ & Cukup baik \\
\hline $41 \%-55 \%$ & Kurang baik \\
\hline$>40 \%$ & Tidak baik \\
\hline
\end{tabular}

\section{HASIL DAN PEMBAHASAN}

Pada penelitian ini perangkat pembelajaran yang dikembangkan berupa bahan ajar dan RPS. Prosedur pengembangan perangkat pembelajaran dalam penelitian ini memodifikasi langkah-langkah dalam penelitian dan pengembangan Gall et al (2007), antara lain 1) analisis kebutuhan, 2) perencanaan, 3) pengembangan format produk awal, 4) 
validasi produk awal, 5) revisi produk tahap awal, 6) uji coba kelompok kecil dan 7) revisi produk. Secara rinci langkahlangkah dalam penelitian dan pengembangan diuraikan sebagai berikut:

1) Analisis Kebutuhan

Pada penelitian ini analisis kebutuhan juga di lakukan pada kurikulum yang berlaku. Diketahui bahwa pada kurikulum jurusan Pendidikan IPA, Fakultas Keguruan dan Ilmu Pendidikan, Universitas Sultan Ageng Tirtayasa terdapat mata kuliah Mikrobiologi yang merupakan salah satu mata kuliah bidang keilmuan dari jurusan Pendidikan IPA. Dengan adanya mata kuliah ini, maka mahasiswa calon guru IPA dituntut untuk menguasai, memahami serta mampu mengaplikasikan konsepkonsep Mikrobiologi pada mata pelajaran IPA nantinya di sekolah menengah pertama. Pada mata kuliah Mikrobiologi dikembangkan perangkat pembelajaran yang berbasis e-learning agar mata kuliah bidang keilmuan ini nantinya dapat terintegrasi dengan mata kuliah dalam lingkup IPA yang ada di jurusan Pendidikan IPA. Pada langkah analisis kebutuhan, peneliti mengembangkan suatu lembar wawancara tertulis sebagai pendukung data yang dibutuhan. Lembar wawancara tertulis terdiri dari indikator keterampilan argumentasi mahasiswa dan kebutuhan calon guru IPA pada mata kuliah Mikrobiologi.

2) Perencanaan

Pada langkah perencanaan peneliti melakukan analisis konten makro pada mata kuliah Mikrobiologi, Capaian Pembelajaran Program Studi (CPPS) dan Capaian Pembelajaran Mata Kuliah
(CPMK) yang ada di jurusan Pendidikan IPA, Fakultas Keguruan dan Ilmu Pendidikan, Universitas Sultan Ageng Tirtayasa.

3) Pengembangan format produk awal

Langkah pengembangan format produk awal dilakukan dengan menyusun rancangan buku ajar dan RPS mata kuliah Mikrobiologi berbasis e-learning yang diharapkan dapat meningkatkan keterampilan argumentasi mahasiswa calon guru IPA pada mata kuliah Mikrobiologi. Bahan ajar dikembangkan berdasarkan konten makro Mikrobiologi, sedangkan RPS disusun berdasarkan acuan capaian pembelajaran program studi dan capaian pembelajaran mata kuliah.

4. Validasi produk awal

Kegiatan ini dilakukan untuk mengevaluasi dan memperbaiki produk awal berupa perangkat pembelajaran yang telah dikembangkan dan memberikan masukan untuk perbaikan perangkat pembelajaran selanjutnya. Proses validasi ini disebut dengan Expert Judgement. Validasi ahli dilakukan oleh 2 orang ahli di bidangnya yang merupakan dosendosen di jurusan Pendidikan IPA, Fakultas Keguruan dan Ilmu Pendidikan, Universitas Sultan Ageng Tirtayasa. Dosen-dosen yang menjadi validator pada perangkat pembelajaran yang dikembangkan ini jika dilihat dari latar belakang pendidikan dan pekerjaan yang ditekuni saat ini sangat sesuai dengan keahlian yang dibutuhkan untuk menjadi validator perangkat pembelajaran mata kuliah Mikrobiologi yang dikembangkan.

Tabel 5 Hasil Validasi Ahli

\begin{tabular}{ccc}
\hline Perangkat & Rerata & Kriteria \\
\hline Bahan Ajar & 3,9 & $\begin{array}{c}\text { Sangat } \\
\text { valid }\end{array}$ \\
\hline RPS & 3,8 & $\begin{array}{c}\text { Sangat } \\
\text { valid }\end{array}$ \\
\hline Instrumen & 3,9 & Sangat \\
\hline
\end{tabular}




\begin{tabular}{ccc}
\hline Penilaian & valid \\
Kemampuan & & \\
Argumentasi & & \\
Mahasiswa & & \\
\hline Instrumen Penilai & 3,9 & $\begin{array}{c}\text { Sangat } \\
\text { valid }\end{array}$ \\
\hline
\end{tabular}

Jika perangkat pembelajaran yang disusun memenuhi validitas konstruk dan validitas isi maka perangkat pembelajaran itu dikatakan valid (Nieveen, 1999).

5. Revisi produk tahap awal

Revisi perangkat pembelajaran berupa bahan ajar dan RPS, serta instrumen penilaian berupa angket keterampilan argumentasi mahasiswa calon guru IPA terhadap perangkat pembelajaran berdasarkan hasil penilaian berupa masukan dan saran dari validator. Jika produk yang dikembangkan telah direvisi dan dinyatakan valid, maka produk siap untuk diujicobakan.

6. Uji coba kelompok kecil

Setelah perangkat pembelajaran divalidasi dan menurut hasil penialaian dinyatakan valid, maka perangkat pembelajaran siap diujicobakan di kelas. Ujicoba skala kecil pada penelitian ini dilakukan terhadap sekelompok kecil mahasiswa dengan melibatkan mahasiswa semester $\mathrm{V}$ di jurusan Pendidikan IPA, Fakultas Keguruan dan Ilmu Pendidikan, Universitas Sultan Ageng Tirtayasa yang sedang mengambil mata kuliah Mikrobiologi. Tujuan dilaksanakannya uji coba ini adalah untuk mengumpulkan informasi berupa keefektifan perangkat pembelajaran yang dapat digunakan sebagai bahan untuk memperbaiki produk dalam analisis revisi berikutnya. Informasi yang terkumpul selama ujicoba berupa hasil angket keterampilan mahasiswa dan hasil angket respon mahasiswa terhadap perangkat pembelajaran mata kuliah Mikrobiologi yang dikembangkan.
Diketahui bahwa keterampilan argumentasi mahasiswa semester $\mathrm{V}$ jurusan Pendidikan IPA yang mengambil mata kuliah Mikrobiologi pada awal sebelum menggunakan perangkat pembelajaran mata kuliah Mikrobiologi berbasis e-learning berada pada kategori cukup baik dan terus meningkat pada akhir setelah pembelajaran menggunakan perangkat pembelajaran mata kuliah Mikrobiologi berbasis e-learning berada pada kategori sangat baik. Hal tersebut dikarenakan pada proses pembelajaran yang disusun pada RPS dan bahan ajar yang disediakan mendukung untuk mengembangkan keterampilan argumentasi mahasiswa calon guru IPA.

Banyak faktor yang mempengaruhi keterampilan argumentasi salah satunya dijelaskan oleh Anwar (2009) yang menyatakan bahwa beberapa faktor yang sangat berpengaruh dalam pembentukan dan penanaman keterampilan argumentasi ini antara lain pengalaman pribadi, orang lain yang dianggap penting, faktor emosi dalam diri, dan kebudayaan di lingkungan sekitar. Untuk dapat membangun dan meningkatkan keterampilan argumentasi sehingga dapat tetap bertahan dalam diri individu dibutuhkan waktu yang lama. Hal ini sesuai dengan pendapat Lang dan Evan (2006), bahwa keterampilan argumentasi akan dapat ditingkatkan pada diri mahasiswa apabila secara terus menerus dikuatkan. Oleh karena itu untuk menumbuhkan, mengembangkan dan meningkatkan keterampilan argumentasi mahasiswa calon guru IPA secara maksimal diperlukan waktu yang lama dan konsisten. Hal ini juga dinyatakan oleh Acar dan Patton (2012) menjelaskan bahwa keterampilan argumentasi dan penalaran peserta didik di perguruan tinggi dapat terus ditingkatkan jika metode 
argumentasi dimasukkan ke dalam kurikulum mata kuliah.

Selanjutnya pada langkah uji coba kelompok kecil juga diperoleh data keefektifan perangkat pembelajaran mata kuliah Mikrobiologi yang dikembangkan melalui respon yang diberikan mahasiswa di akhir proses pembelajaran. Angket respon ini berbentuk skala Likert dengan 4 kategori penilaian, yaitu: sangat setuju (skor 4), setuju (skor 3), tidak setuju (skor 2), sangat tidak setuju (skor 1). Pilihan respon skala empat dipilih agar tidak ada peluang bagi responden untuk bersikap netral, sehingga sikap mahasiswa terhadap pernyataan yang diberikan dapat lebih objektif.

Lembar angket respon dikembangkan berdasarkan aspek kemenarikan, kemudahan, keterbantuan, dan pemecahan masalah. Data yang telah dianalisis ditentukan kriterianya berdasarkan Tabel 6.

\section{Tabel 6. Kriteria Keefektifan Pembelajaran}

\begin{tabular}{cc}
\hline Rentang & Kriteria \\
\hline $3,4-4$ & Sangat efektif \\
\hline $2,6-3,3$ & Efektif \\
\hline $1,7-2,5$ & Kurang efektif \\
\hline $1-1,6$ & Tidak efektif \\
\hline
\end{tabular}

(Buditjahjanto, dkk, 2015)

Rekapitulasi hasil analisis data respon mahasiswa terhadap perangkat pembelajaran mata kuliah Mikrobiologi berbasis $e$-learning ditunjukkan pada Tabel 7.

Tabel 7. Rekapitulasi Hasil Analisis Respon Mahasiswa

\begin{tabular}{ccc}
\hline $\begin{array}{c}\text { Aspek } \\
\text { Penilaian }\end{array}$ & $\begin{array}{c}\text { Rata- } \\
\text { Rata }\end{array}$ & Kriteria \\
\hline Kemenarikan & 3,83 & Sangat efektif \\
\hline Kemudahan & 3,75 & Sangat efektif \\
\hline Keterbantuan & 3,79 & Sangat efektif \\
\hline $\begin{array}{c}\text { Pemecahan } \\
\text { Masalah }\end{array}$ & 3,75 & Sangat efektif \\
\hline
\end{tabular}

Respon mahasiswa terhadap perangkat pembelajaran mata kuliah Mikrobiologi berbasis e-learning untuk setiap aspek berada pada kriteria sangat efektif. Berdasarkan hasil analisis dari kedua komponen keefektifan perangkat pembelajaran terlihat bahwa perangkat pembelajaran yang dikembangkan berkategori sangat efektif. Selain itu, jumlah mahasiswa yang menilai perangkat pembelajaran berkategori sangat efektif telah memenuhi syarat keefektifan yaitu lebih dari $80 \%$. Oleh karena itu, dapat disimpulkan bahwa perangkat pembelajaran yang diukur melalui komponen penilaian efektifitas perangkat pembelajaran memenuhi kategori keefektifan.

7. Revisi Produk

Revisi produk setelah pelaksanaan ujicoba kelompok kecil dilakukan apabila selama proses ujicoba kelompok kecil terdapat kekurangan baik pada bahan ajar dan juga RPS. Revisi ini akan menentukan keberlanjutan langkah uji coba produk untuk skala yang lebih besar. 


\section{KESIMPULAN}

Perangkat pembelajaran mata kuliah Mikrobiologi berbasis e-learning yang dikembangkan layak digunakan karena setelah melalui tahapan validasi, uji coba kelompok kecil, dan revisi produk, kriteria kevalidan perangkat pembelajaran yang dikembangkan berada pada kriteria sangat valid dan berdasarkan uji keefektifan perangkat pembelajaran yang dikembangkan tersebut berada pada kriteria sangat efektif. Perangkat pembelajaran berbasis e-learning yang dikembangkan juga dapat membangun keterampilan argumentasi mahasiswa calon guru IPA pada kriteria sangat baik.

\section{UCAPAN TERIMA KASIH}

Peneliti mengucapkan terima kasih kepada DIPA BLU Universitas Sultan Ageng Tirtayasa dengan nomor kontrak T/I/ UN43.2/PM.01.01/2020 yang telah mendanai penelitian ini.

\section{DAFTAR PUSTAKA}

Acar, O and Patton, B.R. (2012). Argumentation and Formal Reasoning Skills in an Argumentation based Guided Inquiry Course. Social and Behavioral Science. Vol. 46, pp. 4756-4760.

Anwar, H. (2009). Penilaian Sikap Ilmiah Dalam Pembelajaran Sains. Jurnal Pelangi Ilmu. Vol. 2, No. 5.

Arikunto, S. (2015). Dasar-dasar Evaluasi Pendidikan. Jakarta: Bumi Aksara.

Bulgern, J.A., J.D. Ellis and J.G Marquis. (2014). The Used and Effectiveness of an Argumentation and Evaluation Intervention in Science Classes. J Science Education Technology. Vol. 23, pp. 82-97.

Carin, A., and Sund, B. (1997). Teaching Science Through Discovery. Columbus, Ohio: Merrill Publishing Co.
Demircioglu, T \& Ucar, S. (2012). The Effect of Argument-driven Inquiry on preservice science Teacher's Attitude and Argumentation Skill. Social and Behavioral Science. Vol. 46, pp. 50355039.

Erduran, S, Ozdem, Y and Park, J.Y. (2015). Research Trends on Argumentation in Science Education: A Journal Content Analysis From. International Journal of STEM Education. Vol. 2, pp. 5.

Frydenberg, M. E. and D. Andone. (2011). Learning for 21st Century Skills. IEEE's International Conference on Information Society. pp. 314-318.

Gall, M., Gall, J., and Borg, R. (2007). Educational Research: An Introduction. $8^{\text {th }}$ ed. New York, NY: Pearson Education.

Gray, E. and Nam-Hwa, K. (2014). The Structure of Scientific Arguments by Secondary Science Teachers: Comparison of Experimental and Historical Science Topics. International Jurnal of Science Education. Vol. 36, No. 1, pp. 46-65.

Jin, H., H.yem., S. Wang and X. Wei. (2015). A US-China Interview Study: Biology Students' Argumentation and Explanation about Energy Consumption Issues. International Journal of Environmental and Science Education. Vol. 10, No. 3, pp. 301318.

Koenenman, M., Goedhart, M. \& Ossevoort, M. (2013). Introducing Preuniversity Students to Primary Scientific Literatur Through Argumentation Analysis. Research Science Education. Vol. 43, pp 20092034.

Kulatunga, U., Moog, R. S. and Lewis, J. 
E. (2013). Argumentation and Participation Patterns in General Chemistry Peer-Led Sessions. Journal of Research in Science Teaching. Vol. 50, No. 10, pp. 1207-1231

Lang, H. R. and Evans, D.N. (2006). Models, Strategies, and Methods for Effective Teaching. USA: Pearson Education Inc.

Macagno, A, and Konstantinidou, A. (2012). What Students' Arguments Can Tell Us Using Argumentation Schemes in Science Education. International Journal of Science and Mathematic Education. Vol. 27, No. 3.

Nazarudin. (2007). Manajemen Pembelajaran: Implementasi Konsep, Karakteristik dan Metodologi Pendidikan Agama Islam di Sekolah Umum. Yogyakarta: Teras

Nieveen, N. (1999). Design Approaches and Tools in Education and Training. Dordrecht: Kluwer Academic Publishers.

Prasetyo, Z.K, Senam, Wilujeng, I, Anjarsari, P, Wibowo, W.S, Putri, R.A, Katriani, L, Ariyati., D, Wardani, Y.R, Khoirunnisa, O.A, Firdausi, I.R.A. dan Hardina, M. (2013). Pengembangan Perangkat Pembelajaran Sains Terpadu Untuk Meningkatkan Kognitif, Keterampilan Proses, Kreativitas serta Menerapkan Konsep Ilmiah Peserta Didik SMP. Program Pascasarjana UNY.
Rajabi, M., Ekohariadi dan Buditjahjanto, I.G.P.A. (2015). Pengembangan Perangkat Pembelajaran Instalasi Sistem Operasi dengan Model Pembelajaran Berbasis Proyek. Jurnal Pendidikan Vokasi: Teori dan Praktek. Vol. 3, No. 1.

Republik Indonesia. (2013). Peraturan Menteri Pendidikan dan Kebudayaan No. 65 tentang Standar Proses Pendidikan Dasar dan Menengah. Kementerian Pendidikan dan Kebudayaan. Sekretariat Negara, Jakarta.

Ridwan, A.S. (2013). Inovasi Pembelajaran. Jakarta : Bumi Aksara

Sampson, V and Blanchard, M.R. (2012). Science Teachers and Scientific Argumentation: Trends in Views and Practice. Journal of Research in Science Teaching.

Sugiyono, M. P. K. (2008). Kualitatif dan $R \& D$. Bandung: Alfabeta, 124.

Ural, E., and Gençoğlan, D. M. (2020). The Effect of Argumentation-Based Science Teaching Approach on 8th Graders' Learning in the Subject of Acids-Bases, Their Attitudes towards Science Class and Scientific Process Skills. Interdisciplinary Journal of Environmental and Science Education. Vol. 16, No. 1. 